Publish by: Library of STKIP PGRI Sumatera Barat

E-ISSN : 2775-5770

Vol. 1 No. 4 (November 2021) (614-621)

http://ejournal.stkip-pgri-sumbar.ac.id/index.php/horizon

\title{
HUBUNGAN MOTIVASI BELAJAR DENGAN HASIL BELAJAR IPA SISWA KELAS VII SMP NEGERI 1 SIBERUT BARAT DAYA
}

\author{
Ermilianus Sailau, Febri Yanti, Elza Safitri \\ Program Studi Pendidikan Biologi STKIP PGRI Sumatera Barat \\ Emil.sailau80@gmail.com
}

Submitted: 08-10-2021, Reviewed: 08-10-2021, Accepted: 19-10-2021

\begin{abstract}
This research is motivated by the ineffective science learning process so that the encouragement and desire that is still lacking will affect the results achieved by students. Therefore, every student who fails in learning is not solely the student's fault. The possible failure is because the teacher cannot generate student motivation. The purpose of this study is to determine: 1) The relationship of learning motivation through the distribution of motivational questionnaires 2) The results of daily tests in science subjects. This type of research is descriptive research. The population in this study were all seventh grade students at SMP Negeri 1 Siberut Barat Daya for the academic year 2020/2021. Sampling in this study used the total sampling technique. The instrument used for this research is a closed questionnaire that has been distributed to each student and each indicator has a weighted score for each item, to determine the relationship between learning motivation and learning outcomes, hypothesis testing is carried out. Based on the results of the correlation analysis hypothesis test, the value of rxy $=0.325$ with the criterion of "low". To see the contribution of the variable X (learning motivation) to $\mathrm{Y}$ (learning outcomes) with the KP formula, a value of $0.106 \%$ is obtained, which means that the contribution of learning motivation to science learning outcomes is $0.106 \%$ and the rest is influenced by other factors. To find out the meaning of the relationship between $\mathrm{X}$ and $\mathrm{Y}$, a t-test was performed. From the calculation, the tcount value is 1.85 . At the $95 \%$ confidence level $(\alpha=0.05)$ the $t$ table is 1.69. So tcount ttable, Ha is accepted and H0 is rejected, so it can be concluded that there is a low and significant relationship between motivation and science learning outcomes for seventh grade students of SMP Negeri Siberut southwest.
\end{abstract}

Keywords: Motivation, Outcomes, Learning.

\section{PENDAHULUAN}

Proses pembelajaran merupakan suatu proses yang mengandung serangkaian perbuatan guru dan siswa atas dasar timbal balik yang berlangsung dalam situasi edukatif untuk mencapai tujuan tertentu. Proses pembelajaran juga merupakan 


\section{JURNAL \\ HORIZON}

PENDIDIKAN

JURNAL HORIZON PENDIDIKAN

Publish by: Library of STKIP PGRI Sumatera Barat

E-ISSN : 2775-5770

Vol. 1 No. 4 (November 2021) (614-621)

http://ejournal.stkip-pgri-sumbar.ac.id/index.php/horizon

segala pengalaman belajar yang dihayati oleh peserta didik. Dalam kegiatan belajar, motivasi dapat dikatakan sebagai keseluruhan daya penggerak di dalam diri siswa yang menimbulkan, menjamin kelangsungan dan memberikan arah kegiatan belajar sehingga diharapkan tujuan dapat tercapai. Motivasi selalu berkaitan dengan soal kebutuhan. Ada beberapa jenis kebutuhan misalnya: kebutuhan untuk menyenangkan orang lain, kebutuhan untuk mencapai hasil, kebutuhan untuk mengatasi kesulitan. Sehubungan dengan itu, timbulah beberapa teori motivasi yang berpangkal pada kebutuhan yakni kebutuhan filosofis, ingin rasa aman, cinta kasih, mewujudkan diri sendiri (Maslow, 2013).

Motivasi adalah perubahan tenaga di dalam diri seseorang yang ditandai dengan dorongan yang berasal dari diri seseorang untuk mencapai tujuan. Dorongan dan reaksi-reaksi usaha yang disebabkan karena adanya kebutuhan untuk berprestasi dalam hidup. Hal tersebut menjadikan individu memiliki usaha, keinginan dan dorongan untuk mencapai hasil belajar yang tinggi. Menurut Sardiman, (2012: 73) motivasi adalah daya penggerak di dalam diri siswa yang menimbulkan kegiatan belajar dan memberikan arah pada kegiatan belajar sehingga tujuan yang dikehendaki oleh subjek belajar itu tercapai.

Salah satu faktor yang berasal dari dalam diri siswa yang belajar adalah motivasi. Dorongan yang timbul pada diri seseorang secara sadar atau tidak sadar, untuk melakukan suatu tindakan dengan tujuan tertentu disebut motivasi (Kamus bahasa indonesia, 1990:593).

Berkat adanya motivasi, dapat menumbuhkan minat belajar siswa. Bagi siswa yang memiliki motivasi yang kuat akan mempunyai keinginan untuk melaksanakan kegiatan pembelajaran. Masalah tersebut menyebabkan siswa yang memiliki intelegensi yang cukup tinggi menjadi gagal karena kurangnya motivasi, sebab hasil belajar itu akan optimal bila terdapat motivasi yang tepat, sebagai contoh 


\section{JURNAL \\ HORIZON}

PENDIDIKAN

JURNAL HORIZON PENDIDIKAN

Publish by: Library of STKIP PGRI Sumatera Barat

E-ISSN : 2775-5770

Vol. 1 No. 4 (November 2021) (614-621)

http://ejournal.stkip-pgri-sumbar.ac.id/index.php/horizon

terdapat dua faktor yaitu, 1) Faktor internal : motivasi (tidak menyadari potensi dimiliki, target prestasi yang terlalu rendah, takut mengalami kegagalan dan kesuksesan, terlalu sensitif terhadap penilaian orang), 2) Faktor eksternal meliputi : faktor keluarga (kurangnya penghargaan dan ketidak pedulian orang tua terhadap belajar dan prestasi anak kurangnya perhatian terhadap potensi anak, dan status sosial ekonomi (Sutriningsi, 2017).

Oleh karena itu, apabila siswa mengalami kegagalan dalam belajar, hal ini bukanlah semata-mata kesalahan siswa. Kemungkinan ketidak berhasilan tersebut dikarenakan guru tidak dapat membangkitkan motivasi siswa. Ada tidaknya motivasi seseorang individu untuk belajar sangat berpengaruh dalam proses belajar dan hasil aktivitas belajar itu sendiri. Oleh karena itu, motivasi belajar dalam diri siswa perlu diperkuat secara terus menerus.

Berdasarkan hasil dokumentasi nilai ulangan harian siswa SMPN1 Siberut Barat Daya khususnya pada mata pelajaran IPA, rata-rata masih banyak siswa yang nilainya rendah sehingga mereka harus mengikuti remedial untuk memenuhi kriteria ketuntasan minimal (KKM). Ketentuan yang harus dicapai setiap siswa adalah 76. Dalam hal ini akan tampak motivasi belajar mempengaruhi hasil belajar siswa, sejalan dengan hasil penelitian yang telah dilakukan oleh (Achyanadia, 2013) Dengan judul hubungan kebiasaan belajar dan motivasi belajar dengan hasil belajar IPA siswa kelas VII SMP negeri 1 ciseeng terdapat pengaruh positif dan signifikan kebiasaan belajar terhadap hasil belajar IPA siswa.

\section{METODE PENELITIAN}

Penelitian deskriptif adalah suatu metode yang digunakan untuk menggambarkan atau menganalisis suatu hasil penelitian tetapi tidak digunakan untuk membuat kesimpulan yang lebih luas. Adapun lokasi Penelitian ini dilaksanakan di SMP N 1 Siberut Barat Daya. Pengambilan sampel penelitian ini yaitu dengan teknik Total Sampling. 


\section{JURNAL \\ HORIZON}

PENDIDIKAN
JURNAL HORIZON PENDIDIKAN

Publish by: Library of STKIP PGRI Sumatera Barat

E-ISSN : 2775-5770

Vol. 1 No. 4 (November 2021) (614-621)

http://ejournal.stkip-pgri-sumbar.ac.id/index.php/horizon

Menurut Sugiyono (2014:124)

Belajar Siswa Kelas VII SMP Negeri

mengatakan bahwa Total Sampling

adalah teknik penentuan sample bila

semua anggota populasi digunakan

sebagai sample.

Sampel yang digunakan sebagai penelitian sebanyak 31 siswa dalam dua kelas. Data dalam penelitian ini diperoleh langsung dari peserta didik berupa jawaban angket dan hasil nilai ulangan harian pada mata pelajaran IPA. Alat pengumpulan data yang digunakan dalam penelitian ini adalah angket/kuisioner.

\section{HASIL DAN PEMBAHASAN}

Berdasarkan hasil analisis data dan tabel distribusi Hubungan Motivasi Belajar Dengan Hasil
1 Siberut Barat Daya sebagai Dimana hasil analisis korelasi didapakan nilai $r_{x y}=0,325$ dengan kriteria "rendah". Untuk melihat kontribusi variabel $\mathrm{X}$ (motivasi belajar) terhadap Y (hasil belajar) dengan rumus KP didapatkan nilai sebesar $0,106 \%$, yang artinya besarnya kontribusi motivasi belajar terhadap hasil belajar IPA sebesar $0.106 \%$ dan selebihnya dipengaruhi faktor lainnya. Untuk mengetahui makna hubungan variabel X terhadap Y dilakukan uji t. dari peritungan didapatkan nilai $t_{\text {hitung }} 1,85$. Pada taraf kepercayaan $95 \% \quad(\alpha=0,05)$ didapatkan $\mathrm{t}_{\text {tabel }} 1$ 1,69. Jadi $\mathrm{t}_{\text {hitung }} \geq \mathrm{t}_{\text {tabel }}$ maka diperoleh $\mathrm{H}_{a}$ diterima dan $\mathrm{H}_{0}$ ditolak.

Tabel 1. Distribusi Rata-Rata Hubungan Motivasi Belajar dengan Hasil Belajar IPA Siswa Kelas VII SMP N 1 Siberut Barat Daya.

\begin{tabular}{|c|c|c|}
\hline Indikator & $\%$ indikator & Kriteria \\
\hline 1 Tekun dalam mengerjakan tugas & $81,00 \%$ & Baik \\
\hline 2 Ulet dalam menghadapi kesulitan & $82,96 \%$ & Baik \\
\hline 3 Menunjukan minat & $74,32 \%$ & Baik \\
\hline 4 Lebih senang bekerja sendiri & $81,72 \%$ & Baik \\
\hline 5 Tidak Cepat bosan dengan tugas- tugas rutin & $70,00 \%$ & Baik \\
\hline 6 Dapat mempertahankan pendapat & $74 \%$ & Baik \\
\hline 7 Tidak mudah melepas hal-hal yang di yakini & $68 \%$ & Baik \\
\hline 8 Senang mencari dan memecahkan masalah & $76 \%$ & Baik \\
\hline Rata-Rata & 75,99 & Baik \\
\hline
\end{tabular}




\section{JURNAL \\ HORIZON}

PENDIDIKAN

JURNAL HORIZON PENDIDIKAN

Publish by: Library of STKIP PGRI Sumatera Barat

E-ISSN : 2775-5770

Vol. 1 No. 3 (Agustus 2021) (614-621)

http://ejournal.stkip-pgri-sumbar.ac.id/index.php/horizon

Berdasarkan tabel di atas sebagai berikut :

\section{Tekun dalam Mengerjakan Tugas}

Berdasarkan indikator pertama yaitu tekun dalam menegerjakan tugas memiliki nilai $81,00 \%$ dengan kriteria baik. Indikator ini terdiri dari 5 pernyataan, berkenaan dengan mengikuti setiap kegiatan dalam proses pembelajaran, mengerjakan tugas terus-menerus di rumah, mengerjakan tugas walaupun dalam waktu yang lama, mengulangi lagi pelajaran agar lebih memahami, dan harus rajin lagi belajar di sekolah. Siswa yang tekun mengerjakan tugas maka akan mengerjakan tugas atau latihanlatihan yang diberikan Guru dengan baik, siswa akan tabah mengerjakan tugas yang diberikan guru meskipun tugas yang diberikan dalam jumlah yang banyak. Selain itu siswa yang tekun mengerjakan tugas akan mencari sumber-sumber baru untuk menunjang pelajaran, jika siswa tidak tekun mengerjakan tugas maka siswa akan terkendala dalam meraih prestasinya.
2. Ulet dalam Menghadapi

Kesulitan

Berdasarkan indikator kedua yaitu ulet dalam menghadapi masalah memiliki nilai 82,96 \% dengan kriteria baik. Indikator ini terdiri dari 5 pernyataan, berkenaan dengan giat belajar, selalu mengerjakan soal yang sulit, tidak menyerah dan selalu berusaha dan tidak lekas putus asa walaupun mendapatkan nilai yang rendah di kelas. Ulet berarti tidak mudah putus asa yang disertai dengan kemauan keras dan usaha dalam mencapai tujuan. Siswa yang mempunyai tingkat motivasi belajar yang tinggi tidak mudah putus asa dalam menghadapi berbagai kesulitan dalam belajar. Ulet dalam menghadapi kesulitan dapat dilihat dari sikap terhadap kesulitan dan usaha mengatasi kesulitan. Siswa yang tidak ulet dalam menghadapi kesulitan belajar biasanya akan terkendala dalam belajar. Karena biasanya guru-guru saat memberikan latihan dan soal ujian ada tingkat kesulitannya. Ini dilakukan untuk menguji kemampuan siswa. jika 


\section{JURNAL \\ HORIZON}

PENDIDIKAN
JURNAL HORIZON PENDIDIKAN

Publish by: Library of STKIP PGRI Sumatera Barat

E-ISSN : 2775-5770

Vol. 1 No. 3 (Agustus 2021) (614-621)

http://ejournal.stkip-pgri-sumbar.ac.id/index.php/horizon

siswa tidak ulet menghadapi

kesulitan belajar maka akan mengalami kendala dalam mengerjakan latihan dan soal yang sulit. Hal ini senada dengan yang dikemukakan Sardiman (2011 :83) tentang ciri-ciri siswa yang memiliki motivasi belajar sebagai berikut: a) tekun menghadapi tugas, dapat bekerja terus menerus dalam waktu yang lama, tidak pernah berenti sebelum selesai, b) ulet menghadapi kesulitan atau tidak lekas putus asa, tidak cepat puas dengan prestasi yang dicapainya, c) menunjukan minat terhadap bermacam-macam masalah untuk orang dewasa, d) lebih senang bekerja mandiri, e) cepat bosan pada tugas-tugas yang rutin, f) dapat mempertahankan pendpatnya, g) tidak mudah melepaskan hal yang diyakini, h) senang mencari dan memecahkan masalah soal-soal.

3. Menunjukan Minat

Berdasarkan indikator ketiga yaitu minat dan ketajaman perhatian dalam belajar memiliki nilai 74,32\% baik. Indikator ini terdiri dari 6 pernyataan, berkenaan dengan mendengarkan penjelasan materi dari guru dengan seksama, memperhatikan penjelasan materi dari guru di kelas, merasa terganggu apabila ada teman yang mengganggu ketika sedang memperhatikan pelajaran yang sedang berlangsung, berusaha untuk menjawab pertanyaan yang diajukan oleh guru, selalu menanggapi pertanyaan yang dari teman pada saat diskusi, dan merasa rugi jika tidak mengikuti pelajaran di sekolah. Minat merupakan suatu rasa lebih suka dan rasa ketertarikan pada suatu hal atau aktivitas, tanpa ada yang menyuruh. Minat pada dasarnya adalah penerimaan akan sesuatu hubungan antara diri sendiri dengan sesuatu diluar diri. Semakin kuat atau dekat hubungan tersebut, semakin besar minat ( Slameto, 1995:180).

4. Lebih Senang Bekerja Sendiri

Berdasarkan indikator keempat yaitu Senang Bekerja Sendiri memiliki nilai $81,72 \%$ dengan baik. Indikator ini terdiri dari 4 pernyataan, berkenaan dengan mengerjakan dan menyelesaikan sendiri tugas/pekerjaan didalam 


\section{tracen HORIZON}

PENDIDIKAN

JURNAL HORIZON PENDIDIKAN

Publish by: Library of STKIP PGRI Sumatera Barat

E-ISSN : 2775-5770

Vol. 1 No. 3 (Agustus 2021) (614-621)

http://ejournal.stkip-pgri-sumbar.ac.id/index.php/horizon

maupun diluar jam pelajaran dengan kemampuan sendiri. Bekerja mandiri merupakan bentuk dari proses siswa untuk dapat aktif dalam belajar. Hal ini didukung oleh Fatmaryanti dan Desy (2011 : 17) menyatakan dalam proses kemandirian belajar siswa diperlukan aktifitas, siswa bukan hanya jadi objek tapi subjek didik dan harus aktif agar proses kemandirian siswa dapat tercapai.

5. Tidak Cepat Bosan dengan Tugas- Tugas Rutin

Berdasarkan indikator ke lima yaitu tidak bosan dengan tugas-tugas memiliki nilai $70,00 \%$ dengan baik. Indikator ini terdiri dari 5 pernyataan, berkenaan dengan tugas yang bervariasi dan monoton, menggunakan media pembelajaran (Torso, charta, dan gambar). Bagi seorang siswa yang memiliki motivasi belajar yang tinggi, mempunyai keinginan dan dorongan untuk belajar suatu mata pelajaran.
6. Dapat
Mempertahankan
Pendapat
Berdasarkan indikator keenam yaitu dapat mempertahankan pendapatnya dan tidak mudah

melepaskan hal yang diyakini memiliki nilai $74 \%$ dengan baik. Dalam proses pembelajaran, siswa harus dapat mempertahankan pendapat sendiri. Apabila keyakinan siswa tinggi maka siswa tidak mudah terpengaruh oleh temannya. Menurut Nasution (2015 : 125) menyatakan siswa yang kurang mempunyai rasa percaya diri yang tinggi, sehinnga mereka canggung untuk mempertahankan pendapatnya sendiri.

7. Tidak Mudah Melepas Hal-Hal yang Diyakini

Berdasarkan indikator ketuju yaitu,tidak mudah melepaskan hal yang diyakini memiliki nilai $68 \%$ dengan baik. Saling membuka diri mendorong terjadinya saling mempercayai antara kedua individu yang berinteraksi bertukar pendapat satu sama lain.

8. Senang Mencari dan Memecahkan Masalah

Berdasarkan indikator kedelapan yaitu, senang mencari dan memecahkan suatu masalah memiliki nilai $76 \%$ baik. Selalu ingin mencari sumber sumber yang relevan 


\section{HORIZON}

PENDIDIKAN
JURNAL HORIZON PENDIDIKAN

Publish by: Library of STKIP PGRI Sumatera Barat

E-ISSN : 2775-5770

Vol. 1 No. 3 (Agustus 2021) (614-621)

http://ejournal.stkip-pgri-sumbar.ac.id/index.php/horizon

jika ada soal soal yang sulit. setiap DAFTAR PUSTAKA

siswa ingin mengetahui hasil evaluasinya supaya mengetahui kemampuan yang dilakukannya, berkeinginan mengetahui baik atau buruknya kegiatannya. Siswa mampu mencari sumber-sumber lain yang mendukung teori dari buku untuk memperbaiki tugas yang dikerjakan demi kesempurnaan jawaban dari soal-soal IPA, siswa berantusias mencari solusi yang tepat dari beberapa solusi yang dituliskan untuk menyempurnakan tugas tersebut.

\section{KESIMPULAN}

Dari hasil penelitian dapat disimpulkan bahwa adanya hubungan yang rendah dan signifikan antara motivasi dengan hasil belajar IPA siswa kelas VII SMP Negeri Siberut Barat Daya.
Mudjiono, D. D. (2013). Belajar Dan Pembelajaran

Nasution. (2015). Manajemen mutu terpadu.jakarta.

Rika Anggraini, S. N. (2019). Hubungan Aktivitas Belajar Siswa Terhadap Hasil Belajar Biologi Padamateri Klasifikasi Makhluk Hidup Kelas Vii Smp N 1 Luhak Nan Duo Kabupaten Pasaman Barat. Padang.

Solina, wira. 2013. Hubungan Antara Perlakuan Orangtua Dengan Motivasi Belajar Siswa Disekolah. Jurnal Ilmiah Konseling (Volume 2 Nomor 1 Tahun 2013).Hlm.289-29

Sardiman. (2012). Interaksi Dan Motivasi Belajar Mengajar. Jakarta.

Slameto. (1995 ). Belajar dan faktor-faktor yang yang mempengaruhi.jakarta.

Purwanto, N. 2013. Prinsip-Prinsip Dan Teknik Evaluasi Pengajaran. Bandung: Remaja Rosdakarya. 